\title{
Vereintes Europa - auch beim Ärztefrust
}

\author{
Konsequent wird der Geldhahn für die Sécurité Sociale in Frankreich immer \\ stärker zugedreht. Das bringt nicht nur Patienten, sondern zunehmend auch \\ Frankreichs Ärzte in die Bredouille.
}

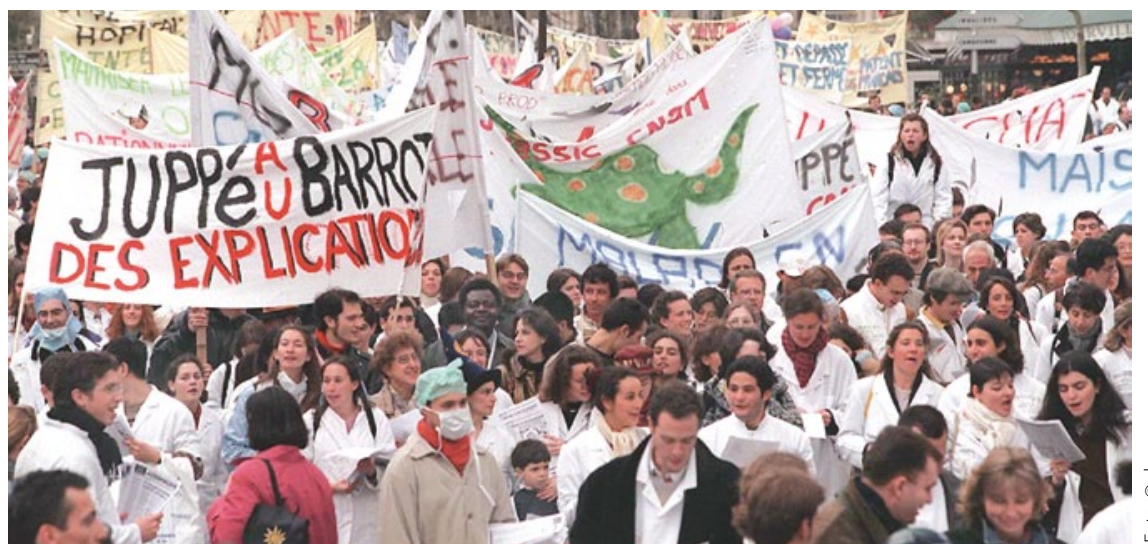

Früher (2003) gingen die Ärzte in Paris noch auf die Straße. Heute haben sie eher resigniert.

— Seit 1976 hat die französische gesetzliche Sozialversicherung Sécurité Sociale fast jedes Jahr rote Zahlen geschrieben. Jetzt muss die Versicherung nicht nur ihre Altlasten abbauen, sondern zusätzlich helfen, den allgemeinen Schuldenberg Frankreichs abzutragen - eine doppelte Belastung, die Ärzte und Patienten trifft.

2010 hat Frankreich insgesamt 234 Milliarden Euro für Gesundheit ausgegeben, knapp $76 \%$ davon wurden von der Sécurité Sociale übernommen. Ende 2009 wies die Sozialversicherung ein Defizit von 23,9 Milliarden Euro auf, darunter 11,4 Milliarden Euro für die Krankenversicherung und 10,8 Milliarden Euro für die Rente, die zweite der insgesamt vier Versicherungssäulen.

\section{Einsparungen von zwölf Milliarden Euro bis Ende 2012}

Die Sécurité Sociale wird zum allergrößten Teil aus Arbeitnehmer- und Arbeitgeberbeiträgen finanziert. Nimmt die Arbeitslosigkeit wie 2010 erneut zu, sin- ken automatisch die Einnahmen. Noch vor einem Jahr plante die Regierung, das Defizit sowie die Altlasten der Vorjahre bis $2015 \mathrm{zu}$ beseitigen. Im August 2011 musste Premierminister François Fillon aber einen Notplan vorstellen, als Frankreich unter dem Druck der EU-Kommission aufgefordert wurde, seine Schulden schneller abzubauen.

Bis Ende 2012 soll Frankreich zusätzlich weitere zwölf Milliarden Euro sparen, von denen knapp sechs Milliarden aus der Krankenversicherung stammen sollen.

In Frankreich werden seit 1995 Gesundheitsausgaben mit einer jährlichen Steigerungsquote vom Parlament festgelegt. Im Sommer vergangenen Jahres stimmten Parlament und Regierung einer Steigerungsquote für ambulante sowie stationäre Leistungen von 2,8\% für 2012 zu. Wegen des Spardrucks wurde die Steigerungsrate dann auf 2,5\% gesenkt - eine Vorgabe, die mindestens bis 2016 in Kraft bleiben wird.
Der Frust ist groß, auch in der Ärzteschaft. „Wenn ich die heutige Befindlichkeit meiner Kollegen beschreiben soll, fällt mir nur diese Beschreibung ein: Wir sind machtlos und desillusioniert", sagt der niedergelassene Lungenarzt Dr. Pascal Charles, der seit Jahren als Präsident der Elsässischen Ärztevereinigung seine niedergelassene Kollegen vertritt. „Im Frühjahr 2011 haben wir einen neuen Tarifvertrag mit der Krankenversicherung unterschrieben, der Honorarerhöhungen ab Ende 2012 unter bestimmten Bedingungen vorsieht. Inzwischen glaubt niemand mehr an diese Erhöhungen“, sagt er.

\section{Ärztemangel absehbar}

Die Verhandlungen mit den Kassen stünden unter einem denkbar schlechten Stern. „Es gibt definitiv kein Geld mehr, um die finanzielle Situation der Ärzte zu verbessern. Die Bürger würden einen Ärzteaufstand weder verstehen noch unterstützen." Die einzige Chance für Ärzte, mehr zu verdienen, ergebe sich aus der demografischen Entwicklung: Immer mehr Ärzte gehen in Pension. „In fünf bis sieben Jahren wird es an niedergelassenen Ärzten mangeln“, sagt Charles, „und wenn Frankreich bis dann die Arbeitsbedingungen unserer jüngeren Kollegen nicht verbessert, wird es für alle sehr eng“, warnt er.

Ärzte seien als Unternehmer sogar doppelt in der Klemme. Wenn die Regierung die Vergütung etwa für technische Leistungen senkt, büßen sie zum einen an Umsatz ein. Gleichzeitig nehmen die Fixkosten zu, parallel dazu dreht der Staat an der Steuerschraube. Was bleibt? „Ärzte können nichts anderes tun, als weiter im Interesse ihren Patienten zu arbeiten“, sagt Charles.

DeNIS DURAND DE BOUSINGEN . 